\title{
Learning Trajectory: Reactions of Prospective Teachers Looking for Solutions to Learning Problems M Sudaryanto ${ }^{1}$ C Ulya ${ }^{2}$, M Rohmadi ${ }^{3}, \mathrm{~K} \mathrm{Wulansari}^{4}$
}

\author{
1,2,3,4 Universitas Sebelas Maret, Surakarta \\ ${ }^{1}$ memetsudaryanto@staff.uns.ac.id, ${ }^{2}$ chafit@staff.uns.ac.id, ${ }^{3}$ mamad_r76@staff.uns.ac.id, \\ kekenw@student.uns.ac.id.
}

\begin{abstract}
The difficulty that is generally found by prospective teachers is the inability to resolve the uniqueness that occurs in the classroom. The study tries to identify solutions offered by prospective teachers and trains the sensitivity of the prospective teacher's pedagogy. The studies uses qualitative approach and supervise case study to explore aspects of supervision over problems in teaching-learning activities. The case study continued with the analysis of the student response document to the problem presented. Data collected were in the form of (1) student essay responses to problem-based learning videos, (2) documents of learning problem cases and rubric description of problems, and (3) results of interviews and observations at school. In general, the results of the study indicate that the complexity of education requires prospective teachers to innovate in developing dimensions / elements of learning to be more varied and improve their quality. The method used in the learning process to achieve goals according to the specified indicators is the learning method. The learning methods in their use certainly affect several aspects, namely learning resources, time allocation, media, and assessment in teaching and learning activities.
\end{abstract}

Keywords: Learning Trajectory, Teachers Problem, Pedagogy

\section{INTRODUCTION}

Class action is triggered by the awareness of the educator that the learning practices carried out contains problems that need to be solved. Learning is a system, which consists of various components that are interconnected with one another. Four central components in learning are objectives, material, methods and evaluation. The four components must be considered by educators in choosing and determining the media, methods, strategies, and approaches to be applied in increasing the effectiveness of learning activities [1]. Learning activities must use appropriate media and learning methods. Learning media is a messenger technology that can be used for learning purposes. Learning media is a means of communication in printed form as well as listening perspective including hardware technology.

The teacher's self-awareness in determining problems and finding solutions in the learning process requires sensitivity [2]. Professionally, teachers must identify each problem experienced by each student and change the learning component in order to show significant results/changes. Pedagogically, the interpersonal relationship between teacher and student must be improved so that problems in the classroom become a communication topic before the 
problem is handled directly by the homeroom teacher and the school counselor. In the process of identifying students' abilities, the teacher needs to make a rubric of problem assessment and find an alternative rubric to solve the problem. This is consistent with the contents of the attachment to the Regulation of the Minister of National Education (Permendiknas) No. 16 of 2007 concerning Academic Qualification Standards and Teacher Competency which states that mastery of learning theory and principles of learning that educate is one element of pedagogical competencies that must be possessed by teachers [3].

Teaching strategies develop dialogic and dialectical thinking abilities. In this way the students will get used to using their critical thinking on everything, including themselves. In addition, to be able to practice critical thinking skills in students naturally requires parents and teachers who also have the ability to think critically. Thus, it is important for adults, who are expected to help children to utilize their thinking skills, humbly learn, practice and develop their critical thinking skills as well. It must be understood that teaching young learners students to think critically is different from teaching adults. Although the ability to learn and think has existed since the beginning of life, the differences in the content and complexity of their knowledge structures differ from those of adults. That difference needs to be the basis for teaching critical thinking in children [4].

Teachers must be able to control students to stay in a conducive state to carrying out teaching and learning activities [5]. The teacher's decision will affect the next action that will be taken. The teacher's decision is also very influential on students' enthusiasm for learning. The right teacher's decision, will have an impact on students, students will be happy and focused in participating in learning activities, otherwise the teacher is not right in making decisions then students will feel less enthusiastic and less likely to occur optimal learning. The advice given is that the teacher must master a variety of models and methods of learning so that when unexpected events occur the teacher can handle them, so that teaching and learning activities can continue.

High student learning outcomes are produced from quality learning processes. Teachers need the ability to apply learning methods that suit their needs, in an effort to produce a quality learning process. Mismatched learning methods applied can reduce the quality of the learning process, therefore correction and improvement of student learning outcomes in schools can be implemented with the use of appropriate learning methods by teachers [6].

Learning methods are all the planning and procedures as well as the steps of learning activities including the choice of assessment methods to be carried out. Teacher must take action if learning activities have problems. Action research is research in the social field, which uses self-reflection as the main method, carried out by those who involved in it, and aims to make improvements in various aspects. When learning takes place, obstacles can occur that interfere with the learning process. Under these conditions, educators need to think of solutions that can be done to overcome these obstacles. The solution used must be precise so that learning can still be done [7]. Obstacles in the learning process are indeed not predictable, that is why it is important for teachers to prepare themselves by thinking about the obstacles that might occur in the learning process and its solutions.

In education field, there are two things that are very sustainable, namely learning methods and learning resources. The method used by teachers varies, depending on the learning pattern. There are two learning patterns in learning, namely individual and group communication or discussion. The focus of learning in individuals is students, while the teacher has a role as a support or facilitator [8]. Unlike the case with group learning processes, where students are more active role in learning activities. The pattern of group learning can be in the form of discussion, making a project, and independent groups. 
The teacher needs to identify each student who has a special deficiency or problem, for example hyperactive student, student who is affected by bullying, apathetic students, and students who have high levels of emotional levels. The symptoms of students' uniqueness must be identified before the teacher determines the same or different learning resources. The next step, the teacher must take a different learning strategy is how the teacher or instructor provides material to students who have these deficiencies.

Ideal conditions in learning is when all students have the same learning resources, but for students who have special needs the learning resources used must adjust to their needs, for example for blind student they use braille books as learning resources or can also use audio media or which only produce sound for example radio/tape. Class situations and conditions that occur require teachers to choose the right method so that the subject matter can be conveyed properly. The choice of learning method will also affect other learning components. The role of teachers is needed in the selection of appropriate learning methods.

Choosing the right learning method can be done by teachers by understanding all situations and conditions that can occur in the classroom during the learning process. Teachers must understand class situations and conditions in order to choose the right method. Maximum results can be obtained by teachers by combining various learning methods so that subject matter can be delivered properly and not boring.

\section{RESEARCH METHOD}

The research method for solving problems in this study uses a qualitative approach. This research is a case study in learning conducted to improve the ability of prospective language teachers in junior and senior high school. The research subjects were students in universities who analyzed problems that might occur in a classroom [9]. The data in the form of (1) student essay responses to problem-based learning videos, (2) documents of learning problem cases and rubric description of problems, and (3) results of interviews and observations at school. Data validity was tested by method triangulation and data source triangulation. Data analysis techniques are through supervision and flow interaction. Students are given the opportunity to explore accepted cases and apply the solutions in the class. This research was conducted in Surakarta by providing a stimulus from the problems that exist in Indonesia with a variety of different events.

\section{RESULTS AND DISCUSSION}

The National Council of Teachers of Mathematics (NCTM, 2000: 52) states that problem solving is one of the main focuses in learning mathematics, for this reason special attention is needed so that students' problem solving abilities are always increasing [10]. Grouws \& Cebulla (2000: 7) mentions if learning objectives are to improve students' problem solving abilities [11]. Improving this problem solving ability can be pursued through various activities including through the learning process that accustoms students to train their problem solving abilities or also through the giving of formative and summative tests based on problem solving abilities.

The complexity of education requires prospective teachers to innovate in developing dimensions / elements of learning to be more varied and improve their quality. The method used in the learning process to achieve goals according to the specified indicators is the learning method. Learning methods in their use certainly affect several aspects, namely learning resources, time allocation, media, and assessment in teaching and learning activities. 
Every component in a learning plan having good classroom interaction will enhance a supportive learning environment and learning process. The intellectual process of the discipline is actively and skillfully conceptualizing, applying, analyzing, synthesizing or evaluating information collected from or produced by, observation, reflection experience, reasoning, or communication as a guide to belief or action.

The diversity of perspectives about critical thinking and the lack of clear guidance make it difficult for every student, regardless of culture, to know what requirements require in practice. If academics are unclear about what they teach, they are unlikely to have clear goals in place and a clear set of student results to measure. Reliable evaluations of both the teachings of critical thinking and student skills become problematic. This uncertainty needs to be resolved if the clear teaching of critical thinking is to be an essential part of tertiary study. Both concepts and criteria should to be explicit.

\section{$3.1 \quad$ Learning Resource}

According to Seels and Richey (in Abdullah, 2012) learning resources are all supporting sources for learning activities, including material support systems and learning environments [12]. Learning resources play an important role in solving problems in learning. Learning resources can be identified as messages, people, materials, tools, techniques, and settings (places). Students can interact with all learning resources in the learning process to achieve the desired results.

Educators must choose the right method when planning the learning process so that the indicators achieved can be more effective. Plans can still change if there are some obstacles that can make educators change the planned method. The obstacles in question such as floods, construction of school buildings or other technical matters such as power points that have been prepared suddenly disappear or are removed. The learning process becomes more complicated if the teacher has no reference in controlling students, material, media, and learning atmosphere either directly or indirectly. Learning resources can be found more easily if the characteristics of students are known, including patterns of interaction in the classroom. The criteria used to see the perspective of students below.

\begin{tabular}{ll}
\hline Critical Thinking Categories & Strategy \\
\hline Basic Classification & 1. Focusing on questions and instructions \\
& 2. Analyzing arguments and supporting sentences \\
& 3. Asking clarifying questions \\
\hline Basic Supporting of an opinion & 4. Assessing the credibility of sources and reference \\
& 5. Assessing observation reports \\
\hline Conclusion & 6. Assessing the ability to elaborate general statements \\
& based on \\
& a. Comparing different solutions to problems \\
& 7. Assessing the validity of a problem solving \\
& 8. Making judgments about assessment \\
\hline Advanced Classification & 9. Assessing the definition \\
& 10. Identifying implicit assumptions \\
\hline Tactics and Strategy & 11. Deciding an action \\
& 12. Interacting with others \\
& 13. Identifying of rhetorical mechanisms and tactics \\
\hline
\end{tabular}


Changes in the methods that occur will certainly affect the learning resources used. For example, teachers use the method of observation in the learning process, but there is a problem that is heavy rain so it is not possible to make observations, the teachers change the method by giving lectures on observations and how to make the text of the observation report. Learning resources have also changed from observation of the surrounding environment to the use of textbooks, presentation slides, videos and more. Based on this, it can be concluded that the changes that occur in the learning method will affect the source of learning because the two are interconnected.

\subsection{Time Allocation}

Barriers that affect the learning method so that it can change the time allocation of class leak, flood, hurricane around the school environment, loud music from outside school activities, crowds that occur outside the classroom, riots outside the school, accidents in the area around the school, power point which will be delivered by teachers is gone, a workshop near the school suddenly explodes, and there is construction of a school building. These obstacles can replace the learning methods that have been prepared by the teachers. Changing learning methods will have an impact on changes in the allocation of learning time [13].

The obstacles above will disrupt the concentration of students and teachers so that the learning process does not go well. Teachers must be able to get around obstacles by changing the time allocation that has been prepared in advance. For example, when a flood occurs, it is very likely that schools will be closed. The situation can be dealt with by giving assignments that students must collect when the school has reopened such as making explanatory texts about floods.

\subsection{Medium}

Audio as medium has function to channel audio messages from the message source to the recipient of the message, both verbal and nonverbal messages. Audio media is closely related to the sense of hearing. Example: radio, telephone, language laboratory. Meanwhile the visual media are media that rely on the sense of sight [14]. This visual media is divided into two, namely silent visuals and motion visuals. Example: photos, image cuts, mind map, maps, power points, moving projections (silent films). Audiovisual media is media that is able to display sound as well as images. Audiovisual media uses the sense of sight and listener. Example: drama, film, and video related to indicators of learning to be achieved.

\section{$3.4 \quad$ Assesment}

Assessment of student learning outcomes in primary and secondary education includes aspects of: (a) attitudes; (b) knowledge; and (c) skills. Letter 'a' is an activity carried out by educators to obtain descriptive information about the behavior of students. Letter ' $b$ ' is an activity carried out to measure students' knowledge mastery. Letter ' $c$ ' is an activity carried out to measure the ability of students to apply knowledge in carrying out certain tasks [15]. The types and forms of assessment of student learning outcomes are as follows: (1) the assessment of learning outcomes by teachers is carried out in the form of tests, observations, assignments, and / or other forms needed; and (2) assessment of learning outcomes by teachers is used to measure and determine student achievement competencies; improve the learning process; and compile reports on the progress of daily learning outcomes, midterm, end of semester, end of year or grade promotion. 


\subsection{Students' Attitude}

When the learning process takes place and requires learning methods that are required to observe the environment but have external obstacles, namely rain accompanied by hurricanes, so the classrooms flood and some leak. Learning methods that should be able to increase the creativity and enthusiasm of students in learning to decrease. Class conditions that should be effective for the learning process become disorganized due to conditions that are not supportive of the classroom for example brawls or accidents around the school so that the class is not conducive to learning. Students will pay more attention to conditions outside the classroom and pay less attention in the classroom [16].

Students as subjects of learning are active individuals with various characteristics, so that in the learning process mutual interactions occur, both between teacher and students and between students and students. Therefore, one of the pedagogical competencies that must be mastered by teachers is to understand the characteristics of students, so that the learning objectives, the material prepared, and the methods designed to convey it are in accordance with the characteristics of students. A good problem solver is able to define the problem and identifies problems in the solution, identifies alternative obstacles that will arise, and tests at least one of them. A good problem solver can evaluate the effectiveness relationships of different settlement strategies [17].

Implementation in the education field, of course critical thinking is closely related to developing education towards a more academic critical. This is based on the nature of education that is able to make students understand the procedural and content of the knowledge delivered, one of the important roles of communication and learning interactions.

\section{CONCLUSIONS}

Teachers' sensitivity in determining the problems experienced by students and collaborating on pedagogical abilities with counseling. Teachers are required to be able to find solutions in the procedures and steps of learning activities including the choice of assessment methods to be carried out learning requires sensitivity. Learning takes place at the same time the teacher must analyze the emotional condition of students in a professional manner. Educators need to think about the choice of methods and collaborate the syntax of each learning method to find the most appropriate solution as an alternative to learning. Educators must understand class situations and conditions in order to choose specific strategies to change students' mindset. Therefore, one of the pedagogical competencies that must be mastered by teachers is to understand the characteristics of students, so that the learning objectives, the material prepared, and the methods designed to convey it are in accordance with the characteristics of students.

\section{REFERENCES}

[1] M. L. Silberman, 101 ways to make training active / Mel Silberman. 2005.

[2] F. Rahman, J. k. Khalil, N. B. Jumani, M. Ajmal, S. Malik, and M. Sharif, "Impact of Discussion Method on Students Performance," Int. J. Bus. Soc. Sci., 2011.

[3] H. Cooper, J. C. Robinson, and E. A. Patall, "Does homework improve academic achievement? A synthesis of research, 1987-2003," Review of Educational Research. 2006.

[4] J. Bawane and J. M. Spector, "Prioritization of online instructor roles: Implications for competency-based teacher education programs," Distance Educ., 2009. 
[5] R. D. Brown, "Book Review: Urban Microclimate: Designing the Spaces Between Buildings," Urban Stud., 2012.

[6] A. Lubezky, Y. J. Dori, and U. Zoller, "HOCS-Promoting Assessment Of Students' Performance On Environment-Related Undergraduate Chemistry," Chem. Educ. Res. Pr., 2004.

[7] E. A. Owen and A. B. Razali, "The Effect of Communicative Activities on Libyan Secondary School Students' Speaking Performance in Malaysia,” Int. J. Instr., vol. 11, no. 4, pp. 45-60, 2018.

[8] S. Dardjowidjojo, "Cultural Constraints in the Implementation of Learner Autonomy," J. Southest Asian Educ., 2001.

[9] J. A. Maxwell and L. E. Reybold, "Qualitative Research," in International Encyclopedia of the Social \& Behavioral Sciences: Second Edition, 2015.

[10] National Council of Teachers of Mathematics, "Six Principles for School Mathematics," Natl. Counc. Teach. Math., 2014.

[11] D. a \& C. Grouws Kristin J and G. \& Cebulla, Improving Student Achievement in Mathematics. 2000.

[12] B. Seels and R. C. Richey, "Instructional technology: The definition and domains of the field," Assoc. Educ. Commun. Technol., 1994.

[13] M. C. Chang, S. Shaeffer, S. Al-Samarrai, A. B. Ragatz, J. de Ree, and R. Stevenson, Teacher Reform in Indonesia:The Role of Politics and Evidence in Policy Making. 2013.

[14] R. E. Mayer, "Using multimedia for e-learning," Journal of Computer Assisted Learning. 2017.

[15] J. Hattie and H. Timperley, "The power of feedback," Review of Educational Research. 2007.

[16] D. K. Shakespeare and L. A. Jakobovits, "Foreign Language Learning: A Psycholinguistic Analysis of the Issues," Hispania, 1971.

[17] K. Saddhono, E. Satria, A. Erwinsyah, \& D. Abdullah. Designing SwiSH Max Learning Software Based of Multimedia. In Journal of Physics: Conference Series. vol. 1364, no. 1, pp. 012032. IOP Publishing, 2019. 